\title{
Radium in Cancer
}

\section{Its Scope of Usetulness and Its Limitations}

By Worthington Seaton Russell, M.D., Research Fellow and Chief of the X-ray Department, New York Skin and Cancer Hospital

R ECENGLY the daily press has extensively exploited $R_{\text {the atfeg }}$ claims of two well-known members of the medical profession that in radium has been found the long-sought:for cure for cancer.

Articles' have appeared in the leading newspapers of all sections of the country, a sample of which I have before me in a clipping from a Syracuse paper with the very positive and convincing headline, "Radium Rays Cure Cancer in Forty-eight Hours," and again in the text, "Cancer is curable and cancerous growths the text, "Cancer is curable and cancerous growths
which had resisted every other treatment invented by science have been cured in forty-eight hours by the marvelous properties of radium." The italics are mine

Many "sure cures" for cancer have arisen, owing in great part to the publicity of the subject following an effort of the profession to properly educate the public regarding the importance of an early diagnosis and prompt and proper treatment. There is but one universally recognized cure for cancer-the knife. Those competent to speak authoritatively because of experience with the various methods of treating cancer are unanimously agreed that the early, complete and radica operation is the safest method known to the profession at the present time.

Just as the earnest efforts of those interested in the popular campaign against cancer are beginning to bear fruit and our patients are realizing the necessity of operation, comes the positive statement, heralded al over the country, that the dread disease can be cured by radium. The statement is all the more harmful because it purports to come from eminent surgeons, and further because there is an element of truth in what further because ther

This arousing in a credulous public of the false hope of a cure does incalculable harm. Many sufferers will defer operation until too late, hoping to avoid the use of the dreaded knife, others will spend hard-earned savings in an effort to receive the treatment and many other unfortunate victims will fall into the hands of the numerous quacks whose only claim to radium is in the use of the name in their advertisements. We hear the heart-rending story many times at the New York Skin and Cancer Hospital-the story of the trial, first of this cure, then of that, the eager and anxious waiting for the promised improvement, the consequent despair and the taking up again of the search for the "sure cure," which is never found, until finally the poor sufferer drifts into the hospital, demanding in the name of humanity that "something" be done to relieve the awful suffering. Everything possible is done, but with quite a different outcome than if the patient at the very outset had fallen into the hands of one competent to give advice.

It is not so long ago that we read in the papers of the long line of consumptives, hopeless yet always hopeful, anxiously awaiting the extensively advertised opening of an "institute" for the cure of tuberculosis by the use of a "turtle" vaccine. The doors never opened, and many a sufferer who had spent his last cent upon a long journey had to beg his way home, there to die a long journey had to beg his way home, there to did because the exertion sapped the little vitality he had,
and because of the realization that he had been duped and because of the realization that he had been duped and there was no hope for him. There is no more dulity of the incurable sick with the promise of a cure

Now comes the cancer cure by radium. That radium has its field of usefulness in the treatment of certain conditions, particularly of benign growths, is not to be denied, but the statement of enthusiatic advocates that the radio-active material will cure cancer is to be challenged. A proper degree of enthusiasm is laudable, but only when it is tempered with scientific skepticism. Those who have had the most experience with radium are not prepared to state just what the effect is upon cancer. The crucial point is, just what may be considered a "cure" in cancer? We have seen many cases come to the hospital in which the primary growth had disappeared under radium irradiation, but with im mense metastases appearing some months afterward. Is it justifiable to record and report such cases as cures? Decidediy no. A case cannot be said to be cured of eancer until five years have elapsed withou a recurfence. We are testing many methods of treat a recurrence. We are testing many methods of treat-
ment at the Skin and Cancer Hospital, but while we are inting interesting and encouraging results from some.zwe would not be dealing honestly with our patienor with those who look to us for our opinions, If we made more positive statements for some time to come. This new method of employing the various radioactive substances in the treatment of cance should be thoroughly, carefully and scientifically tested
Great have been the triumphs of medical science in recent years. Some of our worst foes-diphtheria, typhoid fever, small-pox, etc., have yielded to methods based upon modern bacteriology. Unfortunately the methods so successfully employed in the instances cited, fail completely in our fight against two of the worst enemies of mankindtuberculosis and cancer. What then are we to do? Are we to fold our hands in our laps while awaiting the deliverer who shall free us from these bonds?

There is an old adage that prevention is better than cure. Where the prospect of a cure is at the best very uncertain, this truism acquires special significance, and thus the warfare against tuberculosis and cancer has been largely a warfare of education-the dissemination of knowledge regarding the causes and modes of transmission of these scourges. In the case of tuberculosis this mode of attack has been most fruitful of results. It has been the hope of the medical profession that something at least could also be accomplished in this way in the warfare against cancer. The people have been warned of the nature of the first indication of cancer and of the deadly danger incurred by delay in consulting a competent surgeon, or by failing to follow his advice when the knife must intervene.

It is to be greatly regretted that much of the good that such a campaign may have accomplished, must have been undone by the sensational newspaper accounts and scare headlines ${ }^{\circ}$ which have recently proclaimed alleged healing powers, little short of miraculous, for radium in the treatment of cancer. The truth is that radium has for many years past been employed as a remedial agent against' certain superficial growths somewhat akin to cancer, and that some good results have been gbtained.t But the field of usefulness for the substance has been quite limited, and there is at present no basisl for the belief that recent developments so glaringly displayed in the newspapers will bring any immediate advances of a startling character. At the best many months, if not years, must elapse, before any certainty can be reached, and before the general public can profit by a-new remedy which has not yet passed out of the experimentakstage. In the meanwhile many may be misled by a false hope, or may defer the life-saving operation, and incalculable suffering may thus be caused.

It is with these facts in mind that we gladly open our columns to a statement from the pen of $\mathrm{Dr}$. Worthington Seaton Russell, an expert in the field of cancer treatment and research, who, in answer to many inquiries received at the hospilal to which he is attached, has made an authoritative statement for publication in the SCIENTIFIC AMERICAN and the Crouse-Irving

by those especially trained to carry on the correct technique, and then, after the proper period of time has elapsed to make the results of real value, a conservative report should be published with an estimate of the worth of the method.

The effect of radium cannot be correctly judged unless comparatively large amounts of high radioactivity are employed and unless the proper technique is used. The employment of a radium salt with a low activity, although the bulk may be large, will not produce results, It is said that one surgeon who was using a considerable quantity of a "radium preparation" without result had it tested by a reliable expert, and was told there was no trace of radium whatever in the material. For several years Dr. Bainbridge, director of the Cancer Research Department at the New York Skin and Cancer Hospital, and I have visited the Laboratoire Biologique du Radium at Paris, the London Radium Institute and the other institutions using radium, with a view to watching the work they have been doing. The Paris Laboratory is one of the most important, at the same time being the oldest institution devoted exclusively to the use of radium.

We have been using radium at the Skin and Cancer Hospital and are acquiring a larger quantity of a high activity in order to give the method a thorough test.

Drs. Wickham and Degrais, who have been in charge of the Paris Laboratory, read a paper at the In- ternational Congress held in London last summer on "Can Radium Help Surgery in the Treatment of Malig. nant Tumors?" from which paper I will quote some of the writers' views. They advocate operation in all operable cases to be followed by application of radium if a recurrence is to be feared. In those cases in which the growth is difficult of operation they advise radium treatment both before and after the operation. Several investigators have claimed that radium may in some instances convert an inoperable growth into an operable one.

The authors admit that radium has only a local and palliative effect, still in certain cases of cancer a state of apparent cure has remained for several years.

The London Radium Institute was opened in August, 1911, and the first report appeared in the early part of last year. The Institute has the largest quantity of radium of any in the world, and therefore it has not been limited in its work for a lack of the material. The report, therefore, is of value, especially as $\mathrm{Dr}$. Pinch, the medical superintendent, is careful in his attitude toward the method. A total number of from six to seven hundred cases were treated, including 134 patients suffering from epithelioma. Of this number 7 were "apparently cured," 39 decidedly improved, 22 died, 20 showed no improvement, 23 abandoned treatment, 15 received prophylactic raying, and 8 were to recent to be classified. We must exclude those cases that discontinued treatment, those that received the prophylactic raying and the recent cases, leaving a total of 88 . Of this number 25 per cent died, while there was cure or improvement in 52 per cent. The report advises operation in all operable cases. The results in cancer of the rectum were not as favorable, although it is claimed that in some instances the growth diminished in size, making it possible to remove the tumor by surgical means.

The most successful treatment was with rodent ulcer, an almost non-malignant affection. Dr. Pinch states in the report, "Rodent ulcer is, of all the forms of malignant diseases, the one which is most amenable to the action of radium."

The prophylactic irradiation was employed as a postoperative procedure, and of those so treated only a few showed recurrence. There is a fibrous transformation which serves to arrest hemorrhage and to prevent the dissemination of cancer cells by sealing the lymph vessels.

It must be remembered in analyzing the report that only the most hopeless cases apply for relief and further that Dr. Pinch has classified as "apparently cured" those cases that present a "condition in which all traces of the original lesion have disappeared, in which there is no sign of recurrence and in which the patient is free from any external indication or symptom of the disease."

Dr. Knox, in charge of the radium treatment at the London Cancer Hospital, finds that "operation gives the safest, surest and quickest results in all cases of early cancer, but that radium should be used as a useful adjunct following operation." In common with many observers he states that the X-ray may be as useful as radium. The one advantage that radium has ove the $\mathrm{X}$-ray is that several tubes containing the radium may be buried in the substance of a growth and left there for a long period of time.

One effect has been noted by some observers, and that is that where a primary growth has been rayed the recurrences which appear on the same site are much more resistant to further action of the radium than was the primary lesion or the secondary tumors which may occur outside the field of the first raying.

I have purposely said nothing of the universal success in the treatment of benign conditions, as keloid, nævus, angioma and the like; here one can speak enthusiastically enough, but these facts are well known to the profession.

Except in the case of superficial epitheliomata with out secondary involvement and in certain forms of sarcomata, which are not very malignant, there is no warrant in proclaiming radium as a cure for malignant tumors.

At the annual meeting of the New York State Medical Society last spring, an enthusiast, in speaking of the use of radium, stated that if he had a sufficient quantity he would transcend the acts of the days of the apostles. I can second Dr. Bainbridge, who replied that he, too, had been fired by the same enthusiasm, but after repeatedly visiting the European centers where radium was being tested, he had seen nothing to prove that we had a new specific remedy for cancer. 